\title{
Editorial
}

(C) Journal of International Students

Volume 9, Issue 3 (2019), pp. i-xi

ISSN: 2162-3104 (Print), 2166-3750 (Online)

DOI: $10.32674 /$ jis.v9i3

ojed.org/jis

\section{Focusing on Graduate International Students}

\author{
Shyam Sharma \\ State University of New York at Stony Brook, USA
}

\begin{abstract}
In this brief editorial essay, the author points out a lack of focus on graduate-level international students in research and scholarship in the United States. Highlighting a few potential contributing factors behind the gap, he suggests a number of important issues and perspectives that the scholarship needs to explore as it advances the discourse on the graduate segment of international students. He concludes by calling for a transdisciplinary field of scholarship focusing on international students in general, with a viable subspecialization on the graduate students.
\end{abstract}

Keywords: graduate, international students, myths, politics, agency, advocacy, ecological perspective, leadership

Of the million plus international students in the United States, roughly half of them are at the graduate levels. Unfortunately, there is limited focus on this group in research and scholarship, as well as in academic support programs and institutional policy. Scholarship does recognize this gap, but there is no clarity about its causes and solutions. In this essay, which I write in response to the editor's request to share some highlights drawn from my research, especially a recent book on this student body, I share a few observations on possible factors as I essentially urge scholars writing for journals like this to respond to this gap. I also highlight a number of issues and perspectives needing our attention as we address the gap.

\section{CONTEXTS AND FACTORS}

In public discourse, graduate international students are viewed as "top talent," and they often feature in political debates and national policy discussions (such as in the many Congressional hearings in the past decade) as a valued asset. This positive view 
and discourse, however, seems to ironically contribute to the negligence about supporting and focusing on them.

\section{The Maturity Myth}

First of all, the logic of "top talent" naturally extends to the assumption that international graduate students are mature and therefore do not need any support. On the one hand, the current set up of American graduate education has no curricular structures to support any graduate students. On the other, few institutions and support professionals pay attention to how this gap affects international graduate students far more seriously than it does their domestic counterparts. For instance, there is a vast difference between driving north from Sarasota, Florida to settle in Syracuse, New York before beginning a doctoral program and flying from Shanghai, China to New York City before somehow getting to Syracuse with the same objective. The latter must be done in less than 30 days, per student visa regulation.

International graduate students' being "top talent," whether in the test measures used for recruitment or in their prior academic records, can only translate into success after they land here only in the right environment with sufficient support. That is because these students must reinvent themselves academically, as well as socioculturally. When one enters advanced education in a new academic culture, academic skills like "writing" involve a complex puzzle involving a number of linguistic, rhetorical, cultural, and social abilities that one must develop by learning from a variety of places and processes, formal and informal, and visible or invisible to academic support professionals.

Research and scholarship must confront the assumptions and negligence about international graduate students, paying special attention to their backgrounds, their needs based on disciplines and other factors, and the kinds of programs they are enrolled in. In order to truly assess whether and what kind of support these students need for translating their prior success, assumptions about their maturity must be questioned from all kinds of perspectives.

\section{The Need to Lead Them}

Second, international graduate students themselves exacerbate the problem. Most of them buy into the same false binary about maturity: they assume that their advanced status means that they can do without foundational academic skills, which they may need to catch up on, especially skills that are uniquely situated in the larger academic and social culture of the host country. For this reason, the practice of "making an argument" in academic writing or even writing a "reading response" to prepare for a class meeting can stumble even the most mature and talented foreign graduate students.

Unlike at the undergraduate level, international students first encountering the US academe as graduate students don't have to take foundational courses, aren't exposed to the campus community as part of "college experience," and aren't reached out to for organized initiatives by various support units across campus. Most of them go straight to their departments and labs, while many of them also have to attend to 
many challenges outside campus (usually without a support community). The overwhelming number of things they need to do for adjusting to and catching up leaves most of these students grappling from one day and week to another, until they learn what could have helped, when it has been too late. Many mentors don't help to "educate" them about the availability and benefits of the support; some, in fact, don't know about or, if they do, discourage students from using available support, for all kinds of reasons. An excessive focus on their disciplinary specialization also leads to a narrow view (and thereby development) of their academic skills and professional profiles.

The fact that there are no support structures for these students minimizes the opportunity for practitioners to work closely with these students, as well as for researchers and practitioners to learn and report more about them. In fact, as I have argued in Writing support for international graduate students: Enhancing transition and success, the very methods and framings we use for academic research/scholarship are insufficient when it comes to this student body. I suggest that the framing be not limited to one academic support system at a time but instead the full and complex picture of the university as encountered by the students.

\section{The Nationalistic Regime}

One last factor, among possibly many, behind the relative lack of focus on graduate international students is the larger context of nationalistic regime of international education. Within this framework, international students exist and are viewed by host societies and universities as "foreign bodies" whose well-being and even rights and safety are uncertain. As Simon Marginson aptly points out, "it is hard for national systems of regulations to encompass cross-border persons. It is harder for the students, at the sharp end of national-global ambiguities and tensions" (10). The nationalistic framing is made especially problematic by an increasingly neoliberal, capitalistic view of higher education around the world, partly prompted by the dwindling support for public education and partly by universities becoming willing to find students wherever the money is around the world (while the need to advance global social mobility of students and scholars toward advancing knowledge and its exchange across borders). So, even as they are celebrated for their role in "diversifying the campus," international students evoke ambivalence about whether and how much attention to pay to their success and wellbeing.

International students seem to be decreasingly viewed as individuals with varied identities and ambitions who strive to find a place in often contested intellectual and professional domains in and beyond graduate education (like domestic graduate students). It seems that they are increasingly treated, in practice, as outsiders accepted conditionally and in the "national interest"; their value lies in the competitive geopolitical benefit and economic interests of receiving nations and institutions respectively. Their foreignness (labeled "diversity"), while frequently glorified and occasionally working to the students' advantage, shapes policies and sustains ideologies in ways that practically counter professed ideals about international education and international students. 


\section{ISSUES AND PERSPECTIVES TO ADVANCE}

This is not to say that the connections above are causal, or that these specific connections are the most significant. My intention here is to point out a few contributing factors in order to call for greater focus on international graduate students. With that in mind, let me share a few issues and perspectives that I believe are particularly important to focus on as we address the above gap about this student body.

\section{Minding Politics and Ideology}

First, scholars must pay attention to the fact that international students are fundamentally political beings, inhabiting highly political spaces and therefore highly susceptible to all kinds of political forces. Research and scholarship about them must account for global and national politics about them, including changing relationships between their home and host countries, as well as micro-level political and ideological forces influencing the students' academic experience and performance within the university. This accounting must inform recruitment and orientation, academic support programs, curriculum or pedagogy.

The macro-politics of international education shapes the micro-politics of power and privilege, bias and prejudice, ambivalence and disinterest on the ground-as much as the micro-politics of resistance and empowerment can be used for countering the effects of the larger forces. Being broadly informed about the global geopolitical forces shaping the "market" of globally mobile students can help us respond to the marginalization of existing academic programs. In an era of "big data," the effect of support programs can be further amplified by using numbers about larger political and historical pictures at state, national, and global levels. Doing so can also help academic administrators and staff members participate in institutional conversations on policy, program-building, and negotiation for continuing or changing existing support systems; to formulate new policies and tackle new challenges in realistic manners; and to collaborate with rather than confront university administration when institutional challenges affect existing academic programs. Even scholars involved primarily in classroom instruction can tremendously benefit from an awareness of the larger sociopolitical, economic, and cultural conditions and forces that directly and indirectly affect international students and their own work.

\section{Looking at History}

Similarly, there is a need to develop historically informed perspectives. Research and scholarship on international students must account for historical trends of the global flow and mobility of students, major disruptions and their reasons, and the visible and neglected influences shaping international education and affecting students. Studying the history of international education in the US makes it abundantly clear - whether it is related to immigration policy, change in presidential and economic politics, or international relationship or cultural shift on the domestic front - that this has been a truly volatile political landscape. In the United States, this 
landscape has been full of major shifts - from the establishment of such powerful national programs as Fulbright and Peace Corps to policies like those reflected in provisions of special visas for foreign students and exchange visitors, to the tectonic shifts created by presidents such as John F. Kennedy on the one hand and Donald J. Trump on the other (see Rose-Redwood \& Rose-Redwood, 2017) - that have reshaped the world of scientific advancements, international relationships, and the view of education and citizenship. As Trilokekar (2015) notes, "Reagan's aggressive anti-communist foreign policy [for instance] provided the ideological basis to support international educational exchanges, with the "era of sending and receiving young scholars to build mutual understanding ... now a quaint artifact of a bygone era" (6). In contrast, in the post- 9/11 era, including the Obama years, the fact that international student visas continued to be handled by the Department of Home Security, for instance, shows how politics substituted international educational policies.

Beyond seeking to resist or correct course when policy makers or institutional leaders take approaches that academic scholars/ practitioners consider problematic, it is important to recognize the dynamic nature of international education, given how it has historically interacted with global and local economic and political forces. Even academic programs and day-to-day support practices for these students cannot be sustained without understanding the changing global political and economic forces affecting the movement, adaptation, and success of these students.

\section{Fostering Agency}

Third, especially given the lack of established formal support structures that (when used) benefit international graduate students, research on these students must focus on their agency. As it is problematic to "assume" that these students need no support or attention just because they are talented or mature, it is similarly problematic to assume that they are powerless, helpless, or deficient. Given the structure of US graduate education, instead of trying to create undergraduate-like support programs for graduate students, new support programs and practices must be designed to foster international students' agency so the students can explore the ecology of resources and can more quickly and effectively learn and use academic skills for navigating a new academic culture and negotiating their intellectual positions. In my research, I have found significant interactions between seemingly extraneous forces and students' process of learning academic skills, interactions that deserve exploration in the context of graduate-level academic support for these students as international students.

For instance, in the case of international graduate students, "learning to write" involves a complex puzzle requiring a number of linguistic, rhetorical, cultural, and social skills that they must gather from a variety of places and processes, formal and informal, and visible or invisible to academic support professionals. For that reason, writing support for these students requires support programs to foster their agency toward exploring and exploiting what they need when they need it, to let them adapt and hack the resources we provided, and to design support services with open/flexible points of entry and exit. 
Using an agency-driven approach means that instead of either using a deficit view of international students or using "universal design" for supporting all graduate students, support programs should be designed to let students "forage" and not be limited by support programs. Similarly, scholarship on these students must explore how they develop agency as writers and scholars, as members of their academic disciplines and professional fields. Such a focus can help us recognize the diversity, fluidity, and change in their identity as they interact with and negotiate power and relationship with people and programs across institutions.

\section{Embracing Advocacy}

Fourth, for many of the factors discussed above, practitioners must advocate for international graduate students. Even researchers and scholars often need to drive the conversation about vulnerable groups like this in directions that may be neglected by mainstream discourse-hence requiring a form of advocacy. While requiring separation in data collection and analysis, advocacy may be necessary in terms of advancing research and discourse in significant directions. In many of the areas of academic support for these students (such as my own, which is graduate-level writing and communication support), the support is inherently educational and promotional: often, the students themselves and other stakeholders need to be educated about the support.

The research that I did for my recent book-which involved data from 20 universities that I visited and 15 more from which I collected data distantly, including interviews with nearly 200 individuals in a wide range of positions - showed that an advocacy-driven approach not only helped to foster student agency but also to grow new support programs and make them more effective/sustainable. It also helped academic support programs to transcend the limitations of their marginal "service" positions in their institutions. Effective support programs used inclusive, accessible, and engagement-driven practices in order to foster students' intellectual and social agency, especially by advocating for the students' success and wellbeing. They also paid attention to how their programs could shape institutional policies and priorities; accounted for internal diversity and intersectionality of international graduate students' identities, proficiencies, and experiences; situated the support in the process of students' academic transition into US academe; and prioritized focused support to "universal design" whenever necessary and possible.

\section{Understanding Local-Global Interactions}

Fifth, scholarship on international graduate students can and should tackle overlapping issues about them and about their domestic counterparts, whether that is the intersection of political or economic interests of the two student groups. On the one hand, when it comes to international students' political vulnerabilities, it is not enough to simply view them as "one of us," while doing nothing about their distinct challenges. Improved language skills, for instance, are essential but far from sufficient in order for international students to overcome or deal with the sense of otherness that may be preventing them from speaking with a clear voice and 
confidence. Power dynamics and attitudes (both toward them and among them) affect motivation and success with communication, and these students must learn how to deal with those challenges as international students. On the other hand, we must also directly confront the adverse effects of internationalization of higher education on domestic students. For example, writing for an edited collection on "transnational writing program administration," Dingo, Riedner, and Wingard (2015) used the case of outsourcing of writing support to tutors in Bangladesh, India, and Malaysia by a professor in Texas, discussing how writing scholars can "foreground the many contexts - globalized and institutional, material and ideological - under which twenty-first century [writing support] labor practices may take place" (266). Scott (2016) used the case of outsourcing to make a larger point about the political economy of internationalization, stating that " $[\mathrm{u}]$ nder neoliberal political economic reorganization, global economies have seen a forty-year trend toward the privatization of everything from local mail delivery to national security and intelligence to public education" (13). In my research, I observed that at many public universities, international students are increasingly enrolled in essentially private enterprises within public institutions; increasing their numbers do have other benefits to different stakeholders, but doing so also clearly undermined the mission of education as a social cause.

We cannot advocate for international students without serious regard for how that advocacy may affect domestic students and the future of public education. For instance, we must be mindful not to let political leaders and policy makers off the hook by simply accepting the replacement of public support with "international dollars." As scholars, both institutional leaders and we are responsible to "explore alternatives to perpetual crisis" in education, showing how the crises are "a function of political economy" (26). So, on the one hand, we can and should support institutional leaders to counter the politics of austerity coming at them from state and federal governments by reframing academic scholarship and also programs and pedagogies in politically informed manner. On the other hand, we must pursue research and service for international students with full awareness about how their interests intersect those of domestic students.

\section{Taking an Ecological Approach}

Sixth, especially because international graduate students are extremely diverse in their linguistic, educational, national/cultural, and other social backgrounds, scholars must understand the broad institutional and social ecology that these students inhabit, where they seek support and forge relationships, and how they find resources and solve problems. It is necessary for researchers and practitioners alike to look at diversity and complexity as functions of their agency and vice versa. For instance, in a study involving 20 doctoral students, Gardner (2007) identified five major themes about the socialization process of the students, including ambiguity in guidelines and expectations of students, difficulties students face with balancing various responsibilities, intellectual independence that students needed to become successful, development of cognitive/personal and professional growth, and support by faculty and others in the institution and beyond. In my own study, I found that whether and 
how students use support in one area is connected and competing with their many other needs and interests; thus, to make their support effective, program leaders and practitioners had to understand the larger tangle of challenges, opportunities, resources, relationships, and so on - the larger ecology.

Findings from my research also highlight the value of taking "socioecological approaches" to designing support for international graduate students. As Krasny, Tidball, and Sriskandarajah (2009) note, by reviewing prior scholarship on "social and adaptive learning theories," ecological approaches are particularly useful in advancing situated and adaptive modes of education. Ecological perspectives are also useful for theorizing educational policy at all levels (Weaver-Hightower, 2008; Banathy, 1992). Weaver-Hightower showed how the approach "helps us to conceptualize policy processes as complex, interdependent, and intensely political.... [It] is more appropriate than one of stages and circuits because the interactions of environments, groups, and events capture better the fluidity of processes" (154). Ecological perspectives can help scholars explore broader and complex issues about international graduate students especially because they can account for political and policy ambiguity, as well as disciplinary ideologies and gaps/tensions affecting them, context and process of their social/academic transition/adjustment, and diversity and complexity of their identity and experiences.

\section{Taking Leadership}

Finally, there is a need to provide institutional leadership in favor these students. Too often, we see that academic support units for international students-from ESL centers to remedial courses and ITA support offices - are housed in the basement, dependent on additional fees that students find out they have to pay when they arrive, or treated as a second thought and moved around when there is not enough political pressure to sustain them. Teaching and academic support for these students are provided with contingent faculty; programs are vulnerable to shifting institutional whims; and policy decisions about these students aren't guided by research and scholarship. Part of this problem comes from an ambivalence as to whether especially publicly-funded universities are responsible for the success and wellbeing of international students as non-citizens. There are no voters, taxpayers, lobbyists (beyond some incidental lobbying by certain industries), or parents behind foreign students. In this situation, it is important for scholars to take leadership, to provide insights and information about this student body to relevant decision-makers. It is necessary for them to lead the institutional conversation, program-building, and policy-making. Academic support for international graduate students can be used a high-impact point of intervention in graduate education at large; it can similarly be used as a catalyst for institutional change and problem-solving in graduate education at large.

Intellectual leadership is also necessary because the discourse about international students is replete with outdated and otherwise problematic understanding. There are many (often emerging) issues that need greater attention and more critical perspectives, issues such as shifting concentrations across disciplines, fluctuations in student numbers by country of origin and therefore educational backgrounds and 
support needed, spikes in enrollments at the master's levels (Caplan \& Cox, 2016) where academic support culture is yet to considerably develop, increasingly uneven distribution of international students by types of institution and regions of the country (Okahana \& Allum, 2015), and so on. Such issues call for intellectual leadership not just for the benefit of international students but also because they often have serious bearings on higher education at large and for national interest and the advancement of knowledge globally.

\section{CREATING A SPECIALIZATION}

The various disciplines where international students are a focus of academic support, instruction, or research and scholarship need intellectually and politically savvy approaches that are guided by complex, ecological views especially about the graduate segment of these students. Scholars working with these students must pay serious attention to "the movement and broader influence of globalized powereconomic, political, cultural, governmental, sovereign, disciplinary, biopolitical, all forms and mixes of forms at work" (Dingo, Riedner, Wingard, 2013; 519). We must be willing to rethink convention and introduce our diverse students' stories and perspectives into the agenda of our scholarship. A more broadened and complex view, coupled with new perspectives, will help to liberate us from the limited role of academic service in the margins of institutional organization and conversation, helping us provide better support for students, provide more significant intellectual and educational leadership to our institutions, and thereby make more significant contributions to society.

I would venture further to propose a research area, a specialization, on international students, with concerns about graduate-level international students being a sub-specialization. We might call the specialization "international student study," and it could be an interdisciplinary field of research where scholars of international education, higher education, writing and language/communication support, career centers and other academic services, as well as recruitment and student affairs could find a common ground. Addressing the gaps in the scholarship and creating corresponding professional opportunities, scholars from across the disciplines could work to develop such a specialization by putting the students front and center. The academic program and scholarship should focus on the students themselves (rather than on support systems, institutions, professions or disciplines, social/national interests, or globalization/internationalization of education), especially because international graduate students are capable of partnership and even leadership to address their needs and even the broader interests of academe. As the very name of this journal indicates, the new specialization would foreground the students' own experiences and stories, their stakes and perspectives, their challenges and strengths, their failures and successes, their hurdles and aspirations.

Because "globalization, transformation from the industrial into the global knowledge economy, and international student mobility are mutually reinforcing one another and changing the higher education landscape worldwide" (Gürüz, 2011; 19), foregrounding students as we explore the interactions among these dynamics could help us better serve the students and the society. Such a focus would especially help 
us recognize that international students bring many traditions of knowledge, helping us rethink higher education in light of internationalization. There is a need to develop "transformative internationalization," which, as Habib, Haan, and Mallett (2015) argue, cannot be achieved by simply "recruiting students from other countries": it should instead be "about changing the nature, perspective and culture of all the functions of the university" (web). I argue that future evolution of the university should be guided in the interest of future generations of learners and scholars who will (or should be able to) cross national and cultural borders. If international education is to be driven by broader perspectives and long-term visions for society and the world - especially for increasing in global social mobility and greater exchange of knowledge in the interest of broader human good - the scholarship on advanced international students can and should focus on the students and can and should be on the frontline of discourse about higher education at large.

\section{REFERENCES}

Banathy, B. H. (1992). A systems view of education: Concepts and principles for effective practice. Englewood Cliffs, CA: Educational Technology.

Caplan, N., \& Cox, M. (2016). The state of graduate communication support: Results of an international survey. In S. Simpson, N. Caplan, M. Cox, \& T. Phillips. (Eds.), Supporting graduate student writers: Research, curriculum \& program design (pp. 22-51). Ann Arbor, MI: University of Michigan Press.

Dingo, R., Riedner, R., \& Wingard, J. (2015). Disposable drudgery: Outsourcing goes to college. In Martins, D. S. (Ed.), Transnational writing program administration (pp. 265-288). Logan, UT: Utah State University Press.

Gardner, S. (2007). I heard it through the grapevine. Higher Education, 54, 723740.

Gürüz, K. (2011). Higher education and international student mobility in the global knowledge economy. Albany, NY: State University of New York Press.

Habib, A. S., Haan, J., \& Mallett, K. (2015). The development of disciplinary expertise: An EAP and RGS-informed approach to the teaching and learning of genre at George Mason University. Composition Forum, 31. Retrieved from https://files.eric.ed.gov/fulltext/EJ1061558.pdf.

Krasny, M. E., Tidball, K. G., \& Sriskandarajah, N. (2009. Education and resilience: Social and situated learning among university and secondary students. Ecology and Society, 14(2), 38.

Marginson, S. (2013). Equals or others? Mobile students in a nationally bordered world. In S. Sovic \& M. Blythman (Eds.), International students negotiating higher education: Critical perspectives (pp. 9-27). New York, NY: Routledge.

Okahana, H., \& Allum, J. (2015). International graduate applications and enrollment: Fall 2015. Washington, DC: Council of Graduate Schools.

Rose-Redwood, C., \& Rose-Redwood, R. (2017). Rethinking the politics of the international student experience in the age of trump. Journal of International Students, 7, 3. 
Scott, T. (2016). Subverting crisis in the political economy of composition. College Composition and Communication, 68(1), 10-37.

Trilokekar, R. D. (2015). From soft power to economic diplomacy? A comparison of the changing rationales and roles of the U. S. and Canadian federal governments in international education. Research \& Occasional Paper Series: CSHE.2.15. Retrieved from https://tinyurl.com/trilokekar-2015.

Weaver-Hightower, M. B. (2008). An ecology metaphor for educational policy analysis: A call to complexity. Educational Researcher, 37(3), 153-167.

SHYAM SHARMA, $\mathrm{PhD}$, is an associate professor and Graduate Program Director in the Program in Writing and Rhetoric at State University of New York in Stony Brook. His scholarship and teaching both focus on writing in the disciplines, professional communication, cross-cultural rhetoric, international students and education, new media in education, and issues about language and language policy. His recent book (Writing Support for International graduate Students: Enhancing Transition and Success, Routledge, 2018), which is based on data gathered by visiting 20 US universities (plus distantly from 15 more) offers theoretical and practical strategies for better serving international graduate students and using that support as a high-impact point of intervention in graduate education at large. Email: kmanjet@gmail.com 